\title{
OPTIMIZATION OF A SINGLE-STOREY TIMBER BUILDING STRUCTURE
}

\author{
STOJAN KRAVANJA \& TOMAŽ ŽULA \\ Faculty of Civil Engineering, Transportation Engineering and Architecture, University of Maribor, Slovenia.
}

\begin{abstract}
The paper deals with the optimization of a single-storey timber building structure designed from timber portal frames connected with steel purlins, rails and façade columns. While the portal frames are made of the glued laminated timber with rectangular cross-sections, purlins, rails and façade columns are made of commercially available steel I-profiles. The portal frames are supported by square concrete pad foundations. The building structure is optimized by a mixed-integer non-linear programming (MINLP). The optimization model is developed. The objective function defines the material costs of the structure. The objective function is subjected to structural analysis and design constraints defined according to Eurocode standards. The Modified Outer-Approximation/Equality-Relaxation algorithm (OA/ER) and the linked multi-level strategy are applied. The optimization determines the minimum material costs of the structure, the optimal number of glulam frames and steel members and all standard/discrete crosssections. A numerical example at the end of the paper shows the efficiency of the proposed optimization approach.
\end{abstract}

Keywords: cost optimization, mixed-integer non-linear programming (MINLP), steel structures, structural optimization, timber building, timber structures.

\section{INTRODUCTION}

In one of the first attempts in the field of optimization of timber structures, Topping and Robinson [1] introduced sequential linear programming to be used in the optimization of timber frame structures. Following Topping and Robinson, different optimization techniques and algorithms have been developed and applied. In the last decade, Kaziolasa et al. [2] presented cost minimization of timber structures using a genetic algorithm and simulated annealing. An economical design optimization of cross-laminated timber boards with stiffening ribs was presented by Stanić et al. [3] by means of a gradient optimization. Pech et al. [4] showed the optimization of glued laminated timber beams using metaheuristic algorithms. Jelušič and Kravanja [5] performed a multiparametric mixed-integer nonlinear programming for the optimization of a composite floor system consisting of a concrete slab and timber beams. Jelušič [6] presented an optimal design of glulam beams with non-uniform cross-sections based on a multiparametric mixed-integer nonlinear programming optimization and a response surface optimization. Kravanja and Žula introduced an optimization of a timber hall structure [7].

This paper deals with the optimization of a single-storey timber building structure designed from equal timber main portal frames connected by steel purlins and rails. While the main frames are made of the glued laminated timber with rectangular cross-sections, the purlins and rails are made of hot-rolled IPE steel sections (see Fig. 1). In this paper it is proposed that each portal frame be made of a single monosyllabic piece of glulam to avoid semi-rigid and expensive internal connections. The columns of the portal frames are supported by concrete pad foundations.

The optimization of a single-storey timber structure includes the optimization of the material costs of the structure. In the optimization process, the optimal number of main frames, purlins, rails and façade columns, the optimal cross-sections of timber and concrete elements 


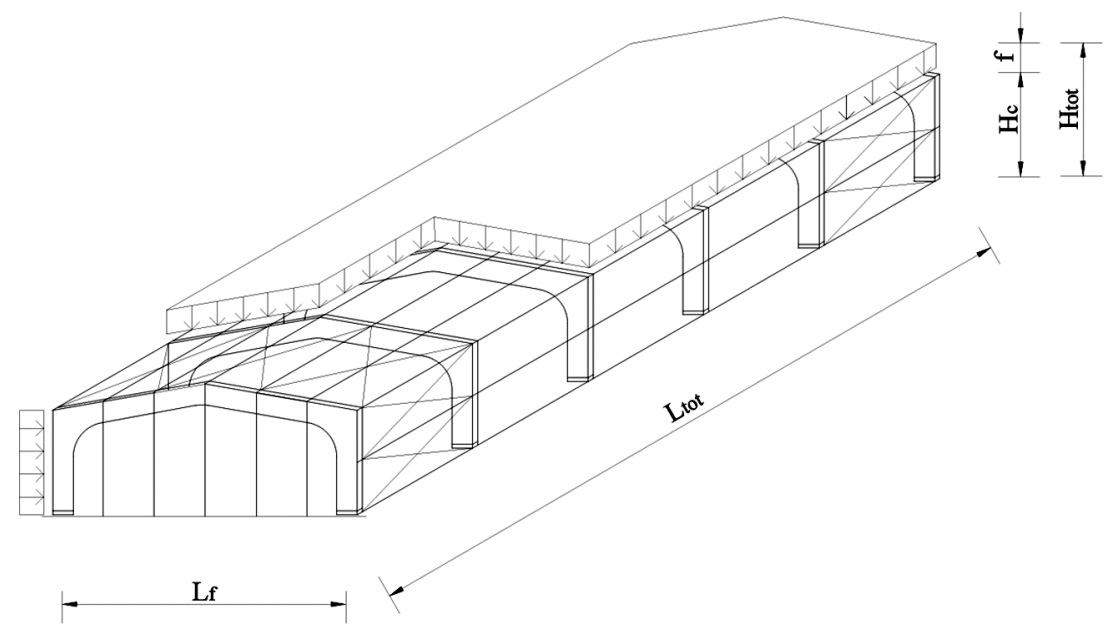

Figure 1: A single-storey glulam timber building structure.

and the optimal steel profiles of the steel members are also calculated. This simultaneous cost, topology and discrete dimension optimization of the building structure is a combined continuous and discrete type of optimization, which is proposed to be calculated with the mixed-integer nonlinear programming (MINLP). The optimization model is therefore modelled on the basis of the MINLP problem formulation:

$$
\min z=f(\mathbf{x}, \mathbf{y})
$$

$$
\begin{gathered}
\text { subjected to: } g_{k}(\mathbf{x}, \mathbf{y}) \leq 0 \quad k \in K \\
\mathbf{x} \in X=\left\{\mathbf{x} \in R^{n}: \mathbf{x}^{\mathrm{LO}} \leq \mathbf{x} \leq \mathbf{x}^{\mathrm{UP}}\right\} \\
\mathbf{y} \in Y=\{0,1\}^{m}
\end{gathered}
$$

(MINLP)

The MINLP handles continuous variables $\mathbf{x}$ and discrete (binary) variables $\mathbf{y}$. The continuous variables are used here to determine structural costs, loads, loadings, resistances and deflections. The discrete variables are employed for topology optimization to calculate the optimum number and arrangement of structural elements. The discrete variables are also used to calculate the optimal rounded dimensions of timber and concrete members and to select the standard I-profiles of steel elements. The cost objective function $z$ is subjected to the (in) equality conditions $g_{k}(\mathbf{x}, \mathbf{y}) \leq 0, k \in K$, for loads, stresses, resistances and deflections. These constraints represent the ultimate and serviceability limit state conditions, defined according to Eurocode 2 for concrete members [8], Eurocode 3 for steel sections [9] and Eurocode 5 for timber elements [10].

The defined MINLP optimization problem is solved with the Modified Outer-Approximation/Equality-Relaxation algorithm by Kravanja and Grossmann [11], which was also adapted for the solution of engineering structures [12]. Since the combinatorics of the discrete optimization problem is relatively high, the linked multi-level strategy [13] is applied to accelerate the convergence of the algorithm.

\section{SUPERSTRUCTURE}

The optimization of a single-storey timber building structure is performed with MINLP. It includes the generation of the MINLP superstructure, the development of the MINLP optimization model and the solution of the defined MINLP problem. 
The generation of the MINLP superstructure includes the definition of topology alternatives, that is, sets of different structural elements from which the optimal numbers of portal frames, purlins, rails and the façade columns can be calculated within the topology optimization process. The superstructure also includes various alternatives for rounding the cross-sectional dimensions of the timber and concrete elements as well as various alternatives of the I-profile for steel members. In this way, the superstructure was created in which all the different alternative structures were fulfilled within a combination between:

- topology alternatives:

- $i, i \in I$, alternatives of the main portal frames,

$\circ j, j \in J$, alternatives of purlins,

○ $k, k \in K$, alternatives of rails,

- rounded dimension alternatives:

- $r_{c b}, r_{c b} \in R_{c b}$, alternatives of different timber column widths (for rounding up to e.g. a whole value in centimetres),

- $r_{c h}, r_{c h} \in R_{c h}$, alternatives of different timber column depths,

- $r_{b b}, r_{b b} \in R_{b b}$, alternatives of different timber beam widths,

- $r_{b h}, r_{b h} \in R_{b h}$, alternatives of different timber beam depths,

- $r_{f}, r_{f} \in R_{f}$, alternatives of different dimensions of the concrete square pad foundations,

- standard dimension alternatives:

- $k_{p}, k_{p} \in K_{p}$, alternatives of different standard hot rolled IPE sections for purlins,

- $k_{r}, k_{r} \in K_{r}$, alternatives of different standard hot rolled IPE sections for rails,

$\circ k_{f c}, k_{f c} \in K_{f c}$, alternatives of different standard hot rolled HEA sections for façade columns.

The task of optimization is to find the minimal material costs of a single-storey timber building structure. Thus, the main goal is to obtain a feasible building structure within the given superstructure that is optimal in terms of material costs, topology, rounded dimensions of timber and concrete members and standard sizes of steel elements.

\section{MINLP OPTIMIZATION MODEL}

The MINLP optimization model of a single-storey timber structure is modelled in the general algebraic modelling system (GAMS) environment [14]. The model includes input data (scalars and parameters), variables, the cost objective function and equality and inequality constraints. While the input data includes a global geometry of the building, the strengths of the materials used, material properties, cross-sectional properties, and prices of timber, steel, and concrete, the variables include loads, resistances, stresses, deflections, cross-sectional dimensions, steel I-sections, number of structural elements, and costs and masses of all members.

The objective function, which is subjected to (in)equality design and dimensioning constraints, defines the material costs of the structure including the costs of glued laminated timber, steel (structural steel plus reinforcing steel) and concrete (see Eq. (1)). In the objective function, $V$ represents the volumes of the materials used, $\rho$ stands for a density of steel and $c$ denotes the prices of materials (for timber and concrete in $€ / \mathrm{m}^{3}$, for steel in $€ / \mathrm{kg}$ ).

$$
\min z=V_{\text {timb }} \cdot c_{\text {timb }}+\left(V_{\text {steel }}+V_{\text {reinf }, \text { steel }}\right) \cdot \rho_{\text {steel }} \cdot c_{\text {steel }}+V_{\text {concr }} \cdot c_{\text {concr }}
$$

The structure of the timber building consists of several identical portal frames, which are mutually connected by steel purlins and rails. The timber portal frames are constructed from glulam columns and pitched beams with rectangular cross-sections. Since the frames are 
made of timber and thus have no fully rigid connections, in calculations they are treated as sway frames. The columns are supported by square pad foundations. Purlins and rails are made of hot-rolled IPE steel profiles to support the roof and façade cladding.

The timber frame structure is subjected to a permanent load $g$ and a variable load $q$. The permanent load is made up of the self-weight of structure $g$, the weight of the roof and the weight of the façade cladding. The variable load comprises the uniformly distributed loads of snow $s$ and wind $w$. The design load on the frame is calculated as a combination of the above-mentioned actions according to Eq. (2).

$$
q_{E d}=\gamma_{g} \cdot g+\gamma_{q} \cdot s+\gamma_{g} \cdot \psi_{0} \cdot w
$$

where $\gamma_{\mathrm{g}}$ represents a partial factor for permanent actions ( 1.35 for the ultimate limit state and 1.0 for the serviceability limit state), $\gamma_{\mathrm{q}}$ stands for a partial factor for variable actions ( 1.50 for the ultimate limit state and 1.0 for the serviceability state) and $\psi_{0}$ is a factor for the frequent value of a variable action ( 0.6 for wind). The portal frame is also exposed to horizontal wind $w_{h o r}$, which acts as a concentrated force on the frame. All actions on the structural elements are automatically calculated in the optimization process taking into account the obtained distances between the elements.

Dimensioning equations of the glued laminated portal frame are defined according to Eurocode 5. These equations include the cross-sectional resistances of the columns and beams for axial compression force, bending moment, shear force and for the combined action of compression and bending.

In this way, the design compressive stress $\sigma_{C, O, d}$ in the timber rectangular cross-sections must be less than or equal to the design compressive strength $f_{C, O, d}$ (see Eqs. (3) and (4)). In Eq. (4), $N_{E d}$ is the design axial compress force, $A$ is the cross-sectional area, $k_{\text {mod }}$ represents a modification factor, which takes into account the influence of load duration and moisture content, $f_{c, 0, g, k}$ stands for a characteristic compressive strength of glulam and $\gamma_{M}$ is a partial factor for the material properties.

$$
\begin{gathered}
\sigma_{C, 0, d} \leq f_{C, 0, d} \\
\frac{N_{E d}}{A} \leq k_{\text {mod }} \cdot \frac{f_{c, 0, g, k}}{\gamma_{M}}
\end{gathered}
$$

The design bending stress about the $y$-axis $\sigma_{m, y, \mathrm{~d}}$ should be less than or equal to the design bending strength $f_{m, y, d}$ (see Eqs. (5) and (6)). $M_{y, E d}$ is the design bending moment about the $y$-axis, $W_{y}$ is the section modulus about the $y$-axis and $f_{m, g, k}$ is a characteristic bending strength of the glued laminated timber.

$$
\begin{gathered}
\sigma_{m, y, d} \leq f_{m, y, d} \\
\frac{M_{y, E d}}{W_{y}} \leq k_{m o d} \cdot \frac{f_{m, g, k}}{\gamma_{M}}
\end{gathered}
$$

The design shear stress $\tau_{d}$ must be equal to or less than the design shear strength $f_{v, d}$ (see Eqs. (7)-(9)) where $V_{E d}$ is the design shear force, $b$ and $h$ stand for width and height (depth) of the cross-section, $f_{v, g, k}$ is a characteristic shear strength of glulam and $k_{c r}$ is a factor that takes into account the cracking of the timber.

$$
\tau_{d} \leq f_{v, d}
$$




$$
\begin{gathered}
\frac{3}{2} \cdot \frac{V_{E d}}{b_{e f} \cdot h} \leq k_{\text {mod }} \cdot \frac{f_{v, g, k}}{\gamma_{M}} \\
b_{e f}=k_{c r} \cdot b
\end{gathered}
$$

The combined effect of axial compression and bending is verified according to Eq. (10), where $k_{m}$ is a factor which makes allowance for redistribution of stresses and the effect of inhomogeneities of the material in a cross-section.

$$
\left(\frac{N_{E d} / A}{f_{C, 0, d}}\right)^{2}+k_{m} \cdot \frac{M_{y, E d} / W_{y}}{f_{m, y, d}} \leq 1.0
$$

Column and beam of the portal frame are also checked for the compress buckling resistance, lateral torsional stability and for the combined effect of compress buckling and lateral torsion. The compress buckling resistance of the elements is checked twice: for buckling about the y-axis (in the plane of the frame) and for buckling about the z-axis, see Eqs. (11)-(18).

$$
\begin{gathered}
\sigma_{C, 0, d} \leq k_{c} \cdot f_{C, 0, d} \\
\frac{N_{E d}}{A} \leq k_{c} \cdot k_{m o d} \cdot \frac{f_{c, 0, g, k}}{\gamma_{M}} \\
k_{c}=\frac{1}{k+\sqrt{k^{2}-\lambda_{r e l}^{2}}} \\
k=0.5 \cdot\left[1+\beta_{c}\left(\lambda_{r e l}-0.3\right)+\lambda_{r e l}^{2}\right] \\
\lambda_{r e l}=\frac{\lambda}{\pi} \cdot \sqrt{\frac{f_{c, 0, g, k}}{E_{0, g, 05}}} \\
\lambda=L_{e f} / i
\end{gathered}
$$

In the above equations, $k_{\mathrm{c}}$ is an instability factor, $\beta_{c}$ is a straightness factor ( 0.1 for a glulam), $\lambda_{\text {rel }}$ is the relative slenderness ratio, $E_{0, g, 05}$ is the fifth percentile value of the modulus of elasticity for a glulam and $\lambda$ denotes the slenderness of the column or beam, $L_{e f}$ is the element buckling length and $i$ is the radius of gyration.

In case when the compress buckling of the column about the $y$-axis (in the frame plane) is checked, the buckling length $L_{e f, y}$ for a small-pitched beam inclination $\left(\alpha \leq 5^{\circ}\right)$ can be calculated by Eqs. (17) and (18), taking into account the sway mode of the timber frame (see Fig. 2).

$$
\begin{gathered}
L_{e f, y}=2 H_{c} \sqrt{1+0.4 k_{s}} \\
k_{s}=\frac{I_{c} \cdot L_{f}}{I_{b} \cdot H_{c}}
\end{gathered}
$$




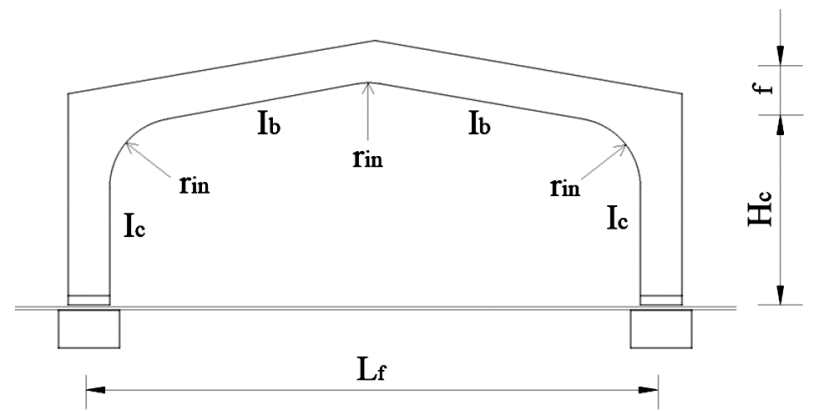

Figure 2: The portal glulam timber frame with a pitched cambered beam.

In the two equations above, $I_{\mathrm{c}}$ is the second moment of area of the frame column, $I_{\mathrm{b}}$ is the second moment of area of the frame beam, $L_{f}$ is the span of the frame and $H_{c}$ denotes the height of the column. When the buckling of the column about the $z$-axis is checked, the buckling length $L_{e f, z}$ should be taken as the vertical distance between the rails. The buckling length of the frame pitched beam about the $y$-axis (in the plane) $L_{e f, y}$ is equal to $\left(L_{\mathrm{f}}^{2}+f^{2}\right)^{0.5}$, about the $z$-axis is equal to the distance between the purlins.

The combined effect between the compress buckling and bending is defined by Eqs. (19) and (20). While Eq. (19) comprises the compress buckling about the $y$-axis, Eq. (20) includes the buckling about the $z$-axis.

$$
\begin{aligned}
& \frac{N_{E d} / A}{k_{c, y} \cdot f_{C, 0, d}}+k_{m} \cdot \frac{M_{y, E d} / W_{y}}{f_{m, y, d}} \leq 1.0 \\
& \frac{N_{E d} / A}{k_{c, z} \cdot f_{C, 0, d}}+k_{m} \cdot \frac{M_{y, E d} / W_{y}}{f_{m, y, d}} \leq 1.0
\end{aligned}
$$

The lateral torsional stability is checked by Eqs. (21) and (22), where $k_{c r i t}$ is a factor that takes into account the reduction of the bending strength due to lateral buckling.

$$
\begin{gathered}
\sigma_{m, y, d} \leq k_{c r i t} \cdot f_{m, y, d} \\
\frac{M_{y, E d}}{W_{y}} \leq k_{c r i t} \cdot k_{m o d} \cdot \frac{f_{m, g, k}}{\gamma_{M}}
\end{gathered}
$$

In Eurocode 5 (EC 5) the factor $k_{c r i t}$ is defined over three intervals by three different equations. Since the optimization models are systems of (in)equations to be solved, the functions of parameters (like $k_{c r i t}$ ) should be defined as single, continuous and differentiable functions over the whole range to avoid infeasible solutions. The function of the factor $k_{c r i t}$ is therefore defined as a single continuous function over the entire interval. The function of $k_{c r i t}$ is approximated by least squares using the solver WolframAlpha [15] (see Eq. (23)), which calculated the best fit using the quartic approximation function $\left(R^{2}=0.990899\right.$, cubic and periodic functions were not so good). Figure 3 shows the approximation and the real EC 5 functions of the factor $k_{\text {crit }}$. The obtained approximation function shows a bad fit for $\lambda_{\text {rel, } m}<0.75$, where $k_{\text {crit }}$ is overestimated. To avoid the problem, the factor $k_{c r i t}$ is limited to less than 1.0. 


$$
\begin{aligned}
k_{\text {crit }}=-0.066572 \cdot\left(\lambda_{\text {rel }, m}\right)^{4} & +0.527004 \cdot\left(\lambda_{\text {rel }, m}\right)^{3}-1.29268 \cdot\left(\lambda_{\text {rel }, m}\right)^{2} \\
& +0.643405 \cdot \lambda_{\text {rel }, m}+0.982971
\end{aligned}
$$

The relative slenderness for bending $\lambda_{r e l, m}$ is for the rectangular cross-section taken as:

$$
\lambda_{r e l, m}=\sqrt{\frac{L_{e f}}{h}} \cdot \frac{h}{b} \cdot\left(3 c_{1}\right)^{-0.25} \cdot \frac{1}{c_{m}}
$$

In Eq. (24) $L_{e f}$ denotes the effective length. $L_{e f}$ is equal to the height of the column if the column is laterally restrained also at the top (with the top rail). For the pitched beam, the verification of the lateral torsional buckling in the areas of the negative bending moments above both columns is performed. The $L_{e f}$ of the beam is calculated as the distance between the negative moment above the column and the point where the bending moment is zero. While $c_{m}$ depends on the quality (strength) of the timber, the factor $c_{1}$ depends on the ratio $h / b$ of the rectangular cross-section. The factor $c_{1}[16]$ is for the ratio $h / b \leq 10$ approximated by least squares of WolframAlpha $\left(R^{2}=0.997951\right)$ (see Eq. (25)):

$$
\begin{aligned}
c_{1}=-0.000177711 \cdot(h / b)^{4} & +0.00467603 \cdot(h / b)^{3}-0.0443609 \cdot(h / b)^{2} \\
& +0.184963 \cdot h / b-0.00058302
\end{aligned}
$$

The combined effect between compress buckling and lateral torsional buckling is defined by Eqs. (26) and (27). Equation (26) defines the combination with the compress buckling about the $y$-axis and Eq. (27) includes the buckling about the $z$-axis.

$$
\begin{gathered}
\frac{N_{E d} / A}{k_{c, y} \cdot f_{C, 0, d}}+\left(\frac{M_{y, E d} / W_{y}}{k_{c r i t} \cdot f_{m, y, d}}\right)^{2} \leq 1.0 \\
\frac{N_{E d} / A}{k_{c, z} \cdot f_{C, 0, d}}+\left(\frac{M_{y, E d} / W_{y}}{k_{c r i t} \cdot f_{m, y, d}}\right)^{2} \leq 1.0
\end{gathered}
$$

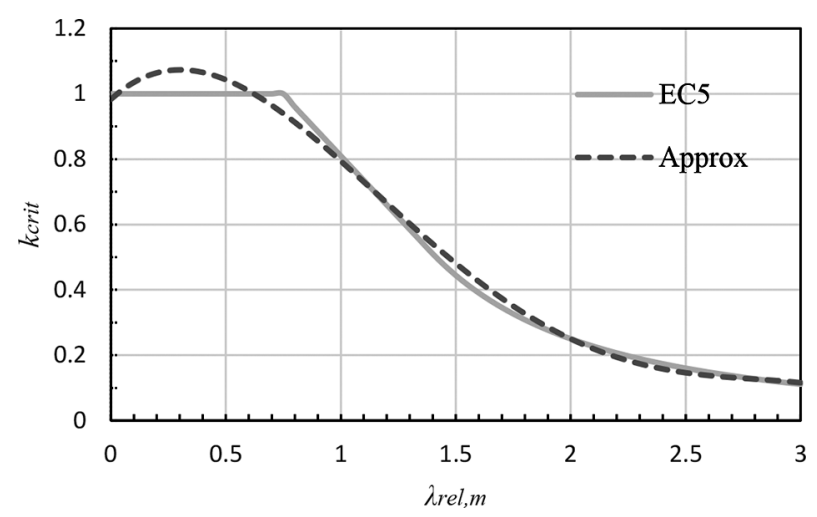

Figure 3: The approximation and the real EC 5 functions of the factor $k_{c r i t}$. 
In the apex zone of the frame (see Fig. 4), the bending stresses $\sigma_{m, d}$, the greatest tensile stresses $\sigma_{t, 90, d}$ perpendicular to the grain and the combined shear and tension stresses perpendicular to the grain are checked.

The bending stresses are calculated according to Eqs. (28) and (29). While the factor $k_{1}$ is dependent on the angle, height and inner radius in the apex zone, the factor $k_{r}$ takes into account the reduction in strength due to bending of the laminates during production; $M_{\text {ap, }}$ is the design bending moment in the apex zone and $W_{a p}$ is the section modulus: $W_{a p}=b \cdot h_{a p}^{\text {ap }} / 6$. The angle $\alpha_{\text {ap }}$ should be calculated as $\alpha_{\text {ap }}=\arctan \left(2 f / L_{\mathrm{f}}\right)$ (see Fig. 1). If the inner radius $r_{i n}$ and the angle $\alpha_{\text {ap }}$ are small, the height of the apex zone $h_{a p}$ can be taken to be equal to the height of the beam, $h_{a p} \approx h_{b}$. While the factor $k_{l}$ is defined by Eqs. (30)-(35), the factor $k_{r}$ should be calculated according to Eq. (36), where $t$ represents the thickness of the glulam lamella (usually $2-2.5 \mathrm{~cm}$ ).

$$
\begin{aligned}
& \sigma_{m, d} \leq f_{m, d} \\
& k_{l} \cdot \frac{M_{a p, d}}{W_{a p}} \leq k_{r} \cdot k_{m o d} \cdot \frac{f_{m, g, k}}{\gamma_{M}} \\
& k_{l}=k_{1}+k_{2}\left(h_{a p} / r\right)+k_{3}\left(h_{a p} / r\right)^{2}+k_{4}\left(h_{a p} / r\right)^{3} \\
& k_{1}=1+1.4 \tan \left(a_{a p}\right)+5.4 \tan ^{2}\left(a_{a p}\right) \\
& k_{2}=0.35-8 \tan \left(a_{a p}\right) \\
& k_{3}=0.6+8.3 \tan \left(a_{a p}\right)-7.8 \tan ^{2}\left(a_{a p}\right) \\
& k_{4}=6 \tan ^{2}\left(a_{a p}\right) \\
& r=r_{i n}+0.5 h_{a p} \\
& k_{r}=0.76+0.001 r_{i n} / t \quad \text { when } r_{i n} / t<240
\end{aligned}
$$

The combined effect of the design axial compression force $N_{a p, d}$ and the design bending moment $M_{a p, d}$ in the apex zone is checked according to Eq. (37).

$$
k_{l} \cdot\left(\frac{N_{a p, d}}{A_{a p}}+\frac{M_{a p, d}}{W_{a p}}\right) \leq k_{r} \cdot k_{m o d} \cdot \frac{f_{m, g, k}}{\gamma_{M}}
$$

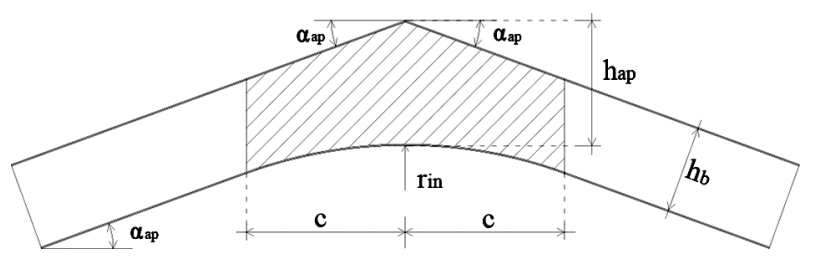

Figure 4: The apex zone of the pitched cambered beam of the glulam timber frame. 
The greatest tensile stresses $\sigma_{t, 90, d}$ perpendicular to the grain due to bending are checked by Eqs. (38) and (39), where $k_{p}$ is a factor which takes into account the effect of the stress distribution in the apex zone (depends on angle, depth and inner radius in the apex zone) (see Eqs. (40)-(43)), $k_{d i s}$ is 1.7 for pitched chambered beams and $k_{v o l}$ is a volume factor, $f_{t, 90, d}$ is the design tensile strength perpendicular to the grain and $f_{t, 90, g, k}$ is a characteristic tensile strength perpendicular to the grain. The factor $k_{v o l}$ is calculated according to Eq. (44), where $V_{0}$ is $0.01 \mathrm{~m}^{3}$ and $V$ is the volume of the apex zone defined by Eq. (45).

$$
\begin{gathered}
\sigma_{t, 90, d} \leq k_{d i s} \cdot k_{v o l} \cdot f_{t, 90, d} \\
k_{p} \cdot \frac{M_{a p, d}}{W_{a p}} \leq k_{d i s} \cdot k_{v o l} \cdot k_{m o d} \cdot \frac{f_{t, 90, g, k}}{\gamma_{M}} \\
k_{p}=k_{5}+k_{6}\left(h_{a p} / r\right)+k_{7}\left(h_{a p} / r\right)^{2} \\
k_{6}=0.2 \tan \left(a_{a p}\right) \\
k_{7}=2.1 \tan \left(a_{a p}\right)-4 \tan ^{2}\left(a_{a p}\right) \\
k_{v o l}=\left(\frac{V_{0}}{V}\right)^{0.2} \\
V=2 r_{i n} \cdot \sin \left(a_{a p}\right) \cdot h_{a p} \cdot b
\end{gathered}
$$

The combined shear and tension perpendicular to the grain in the apex zone of the timber frame is also checked, see Eq. (46).

$$
\frac{\tau_{d}}{f_{v, d}}+\frac{\sigma_{t, 90, d}}{k_{d i s} \cdot k_{v o l} \cdot f_{t, 90, d}} \leq 1.0
$$

In the column-beam zone of the timber frame (see Fig. 5) where the column is rigidly connected to the pitched cambered beam, eqn. (28)-(46) are used analogous to the apex zone. In the paper a special case is considered in which the cross-sectional dimensions $b$ (width) and $h$ (depth) of columns and beams are defined to have the same value. This results in $h_{\mathrm{c}}=$ $h_{b}=h$. For a small inclination of the pitched beam $\left(\leq 5^{\circ}\right)$ the height of the column-beam zone $h_{\text {ap }}$ can be calculated with Eq. (47). In this zone the angle $\alpha_{\text {ap }}$ must be determined according to Eq. (48).

$$
\begin{gathered}
h_{a p}=h \cdot \sqrt{2}+r_{i n}(\sqrt{2}-1) \\
a_{a p}=\pi / 4-0.5 \cdot \arctan \left(\frac{2 f}{L_{f}}\right)
\end{gathered}
$$




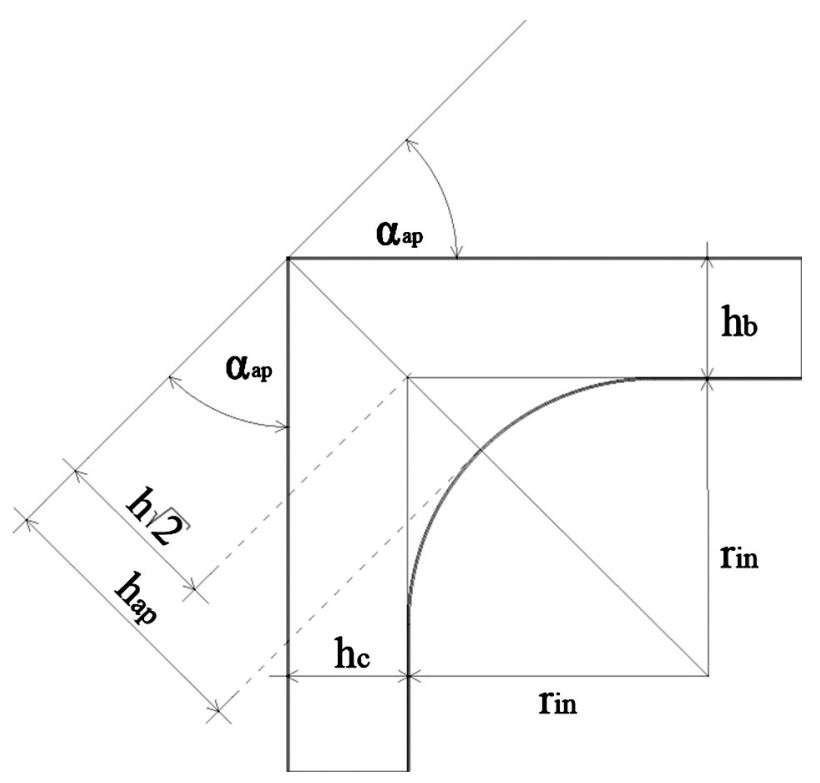

Figure 5: The column-beam zone of the glulam timber frame.

Steel purlins, façade rails and façade columns are checked for their axial resistance (see Eq. (49)) shear resistance (Eq. (50)), bending resistance (Eq. (51)) and the compression buckling resistance (Eq. (52)), where $f_{y}$ is the yield strength of the steel, $\gamma_{M 0}$ is the resistance partial safety factor, $A_{v}$ is the effective shear area of the cross-section, $\chi$ is the reduction factor due to flexural buckling and $\gamma_{M I}$ is the resistance partial safety factor.

$$
\begin{gathered}
N_{E d} \leq \frac{A \cdot f_{y}}{\gamma_{M 0}} \\
V_{E d} \leq A_{v} \cdot \frac{f_{y}}{\sqrt{3}} \cdot \frac{1}{\gamma_{M 0}} \\
M_{E d} \leq \frac{W \cdot f_{y}}{\gamma_{M 0}} \\
N_{E d} \leq \chi \frac{A \cdot f_{y}}{\gamma_{M 1}}
\end{gathered}
$$

The combination between the compression and bending moment resistance of steel elements is checked by Eq. (53).

$$
\frac{N_{E d}}{A \cdot f_{y} / \gamma_{M 0}}+\frac{M_{E d}}{W \cdot f_{y} / \gamma_{M 0}} \leq 1.0
$$

The combination between the buckling and the lateral-torsional buckling resistances of steel members is defined by Eq. (54), where $\chi_{L T}$ represents the reduction factor due to the lateral-torsional buckling. 


$$
\frac{N_{E d}}{\chi \cdot A \cdot f_{y} / \gamma_{M 1}}+\frac{M_{E d}}{\chi_{L T} \cdot W \cdot f_{y} / \gamma_{M 1}} \leq 1.0
$$

The bearing resistance in the ground under the square reinforced concrete pad foundations is verified according to Eq. (55), where $A_{f}$ and $W_{f}$ stand for the surface area and the section modulus of the foundation, respectively.

$$
\sigma=\frac{N_{E d}}{A_{f}}+\frac{M_{E d}}{W_{f}} \leq 200 k P a
$$

Vertical deflections of timber and steel elements $\delta_{\max }$ exposed to the total load (self-weight + snow + wind) are defined to be less than span/250. Horizontal deflections of the timber frame $u$ are calculated to be smaller than frame height/150.

In the optimization model, the constraints also contain equations for the topology optimization of the optimal number of portal frames, purlins, rails and façade columns, they contain equations for the selection of the optimal IPE and HEA profiles of steel members and the equations for the rounding of the dimensions of the glulam cross-sections and pad foundations.

To the portal frames, purlins and rails of a building structure, special binary $0-1$ variables (y) are assigned. The optimal number of elements is calculated as the sum of the assigned non-zero binary variables $(y=1)$. For example, in order to obtain the optimal topology of timber frames, a set of $i, i \in I$, alternative portal frames and their binary variables $y_{i, \text { frame }}$ is defined. The optimal number of portal frames $N_{\text {frame }}$ is calculated in the topology optimization as the sum of the binary variables $y_{i, f r a m e}$, which are assigned to the frame alternatives (see Eq. (56)). Equation (57) defines only one possible vector of binary variables, which is assigned for each topology (number of frames). For example, the theoretical minimal topology with a single frame is defined by the vector of binary variables $\boldsymbol{y}_{i, f r a m e}=\{1,0,0,0,0, \ldots, 0\}$ and not by $\boldsymbol{y}_{i, f r a m e}=\{0,1,0,0,0, \ldots, 0\}$ or others. In this way, a much smaller number of MINLP iterations is required to achieve convergence. The optimal numbers of other elements (purlins, rails and façade columns) are calculated in the same way.

$$
\begin{gathered}
N_{\text {frame }}=\sum_{i \in I} y_{i, \text { frame }} \\
y_{i-1}-y_{i} \geq 0 \quad i \in I
\end{gathered}
$$

Optimal steel I-profiles are calculated in the simultaneous standard dimension optimization. For example, a set of $j, j \in J$, alternative hot rolled IPE profiles to the purlin is defined. To each different IPE profile alternative, a special binary variable $y_{j, p u r}$ is assigned. The optimal cross-sectional area of the purlin $A_{\text {pur }}$ is calculated as a scalar product between a vector of $j$ standard cross-sectional area alternatives $\mathbf{A}_{j, p u r}=\left\{A_{1, p u r}, A_{2, p u r}, A_{3, p u r}, \ldots, A_{j, p u r}\right\}$ and a vector of $j$ associated binary variables $\mathbf{y}_{j, p u r}=\left\{y_{1, p u r}, y_{2, p u r}, y_{3, p u r}, \ldots, y_{j, p u r}\right\}$ (see Eq. (58)). Only one standard cross-sectional area is assigned to the purlin, because the sum of the binary variables must be equal to 1 (see Eq. (59)). In a similar way, the optimal standard I-profiles of other steel elements and the optimal rounded dimensions of timber and concrete cross-sections are calculated. 


$$
\begin{gathered}
A_{p u r}=\sum_{j \in J} A_{j, p u r} \cdot y_{j, p u r} \\
\sum_{j \in J} y_{j, p u r}=1
\end{gathered}
$$

\section{NUMERICAL EXAMPLE}

The paper presents the simultaneous cost, topology and discrete dimension optimization of a $34 \mathrm{~m}$ long, $3.8 \mathrm{~m}$ high and $14 \mathrm{~m}$ wide (span) single-storey timber structure. While the main portal frames are made of glued laminated timber GL28h; purlins, rails and façade columns (in the front and rear façade) are made of hot-rolled steel I-profiles of structural steel S 355. The structure is exposed to the self-weight, snow $s=1.0 \mathrm{kN} / \mathrm{m}^{2}$ and horizontal wind $w=0.5$ $\mathrm{kN} / \mathrm{m}^{2}$. The task of the optimization is to calculate the optimal material costs of the structure, the optimal number of structural elements (timber frames and steel members) and all cross-sections (rounded timber and concrete cross-sectional dimensions as well as steel IPE and HEA steel profiles).

The input data includes not only the defined global geometry and loads but also the characteristic strengths of glulam and steel, modules, densities, structural topology alternatives, IPE and HEA profiles, discrete dimensions, material prices, like: $L_{\text {tot }}=34.0 \mathrm{~m}, L_{f}=14.0 \mathrm{~m}$, $H_{c}=3.8 \mathrm{~m}, f=0.4 \mathrm{~m}, k_{\text {mod }}=0.9, \gamma_{M}=1.25, k_{\mathrm{m}}=0.7, f_{c, 0, g, k}=26.5 \mathrm{MPa}, f_{m, g, k}=28 \mathrm{MPa}$, $f_{v, g, k}=3.2 \mathrm{MPa}, f_{t, 90, g, k}=0.45 \mathrm{MPa}, E_{0, g, 05}=10200 \mathrm{MPa}, f_{y}=355 \mathrm{MPa}$ (steel), $E=210000$ $\mathrm{MPa}$ (steel), $\rho_{\text {timb }}=540 \mathrm{~kg} / \mathrm{m}^{3}, \rho_{\text {steel }}=7850 \mathrm{~kg} / \mathrm{m}^{3}, \rho_{\text {concr }}=2500 \mathrm{~kg} / \mathrm{m}^{3}, c_{\text {timb }}=800 € / \mathrm{m}^{3}$, $c_{\text {steel }}=1 € / \mathrm{kg}, c_{\text {concr }}=100 € / \mathrm{m}^{3}$, etc.

The superstructure consists of 70 portal frames $(i), 2 \times 25$ purlins $(j), 2 \times 10$ rails $(k), 18$ different standard IPE steel profiles for purlins $\left(k_{p}\right), 18$ different standard IPE profiles for rails $\left(k_{r}\right), 24$ different standard HEA steel profiles for façade columns $\left(k_{f c}\right), 17$ different discrete alternative dimensions for the width of rectangular timber sections $\left(r_{b}\right.$, from $10 \mathrm{~cm}$ to $50 \mathrm{~cm}$ with step $2.5 \mathrm{~cm}$ ), 51 different discrete alternative dimensions for the depth of the rectangular timber sections ( $r_{h}$, from $25 \mathrm{~cm}$ to $150 \mathrm{~cm}$ with the step of $2.5 \mathrm{~cm}$ ) and 121 different discrete alternative dimensions for the width of the square concrete pad foundations $\left(r_{f}\right.$, from $50 \mathrm{~cm}$ to $350 \mathrm{~cm}$ with the step of $2.5 \mathrm{~cm}$ ). The combinatorics of the defined discrete alternatives gives $i \cdot j \cdot k \cdot k_{p} \cdot k_{r} \cdot k_{f c} \cdot r_{b} \cdot r_{h} \cdot r_{f}=70 \cdot 25 \cdot 10 \cdot 18 \cdot 18 \cdot 24 \cdot 17 \cdot 51 \cdot 121=1.42757 \cdot 10^{13}$ different structural alternatives. One of them is the optimal one.

The defined MINLP optimization problem is solved with the Modified Outer-Approximation/Equality-Relaxation algorithm, which includes a global convexity test [11,12]. Since the combinatorics of the discrete optimization problem is relatively high, the linked multi-level strategy is applied to accelerate the convergence of the algorithm [13]. The strategy starts with continuous optimization of the structure (nonlinear programming), which is a good starting point for discrete optimization of the structural topology and standard/discrete cross-sections.

For MINLP optimization, the MINLP computer program Mipsyn [17] is used, in which the sequences of the NLP and MILP sub-problems are solved to achieve convergence. The program GAMS/Conopt [18] is employed for the solution of the continuous NLP optimizations with the generalized reduced-gradient method according to Abadie and Carpentier [19] and the program GAMS/Cplex [20] is used for the discrete MILP optimizations with the branch and bound method by Land and Doig [21]. 


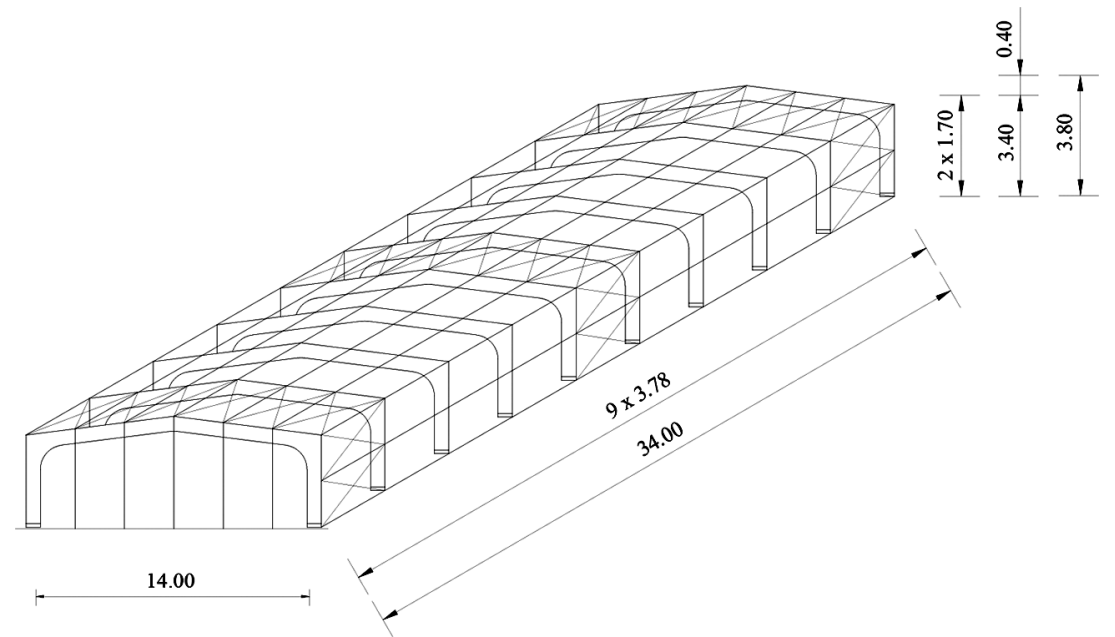

Figure 6: Optimal topology of the single-storey timber building (metres).

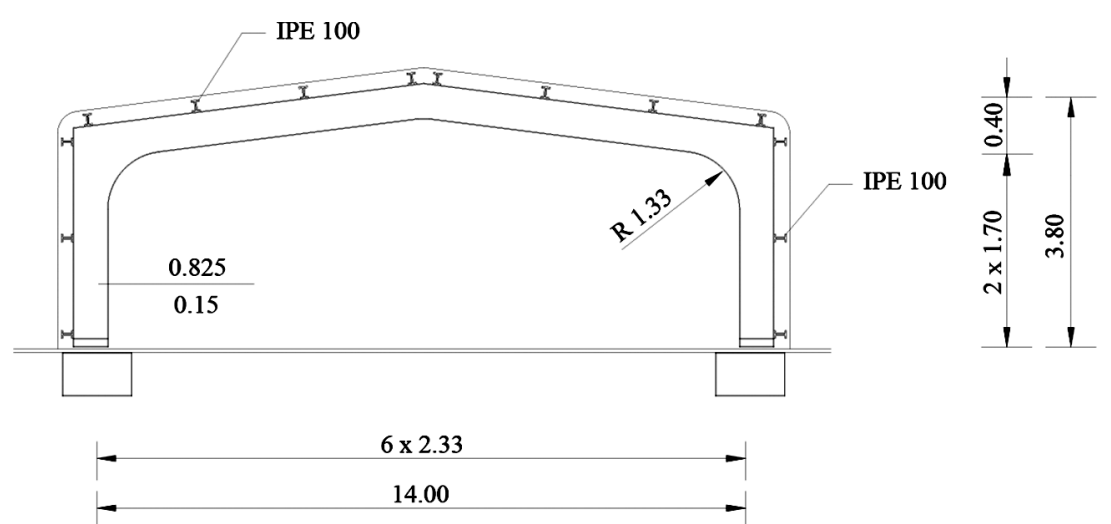

Figure 7: Optimal glulam timber frame and steel sections (metres).

The calculated optimal result corresponds to the minimal structure's material costs of $25,318 €$ (the selling price is about three times higher). Convergence required 8 MINLP iterations and less than 5 minutes of working time. The optimal solution includes the optimal topology of 10 main portal frames, 8 purlins, 6 rails and $2 \times 7$ façade columns in the front and rear façades (see Fig. 6). The optimal cross-sections obtained include a rectangular glulam cross-section 150/825 mm for the columns and pitched beams of the main frames, IPE 100 for purlins and rails, HEA 120 for the façade columns and a square area of $1.700 \mathrm{~m} \times 1.700$ $\mathrm{m}$ for a 1-m deep pad foundations (see Fig. 7).

\section{CONCLUSIONS}

The paper deals with the optimization of a single-storey timber building structure, designed from timber portal frames, which are connected with steel purlins, rails and façade columns. The latter are constructed in the front and rear façade. While the portal frames are made of the glulam with rectangular cross-sections, purlins, rails and façade columns are constructed 
from standard steel I-profiles. The portal frames are supported by square concrete pad foundations. The optimization of the mixed glulam-steel structure is performed by the mixed-integer non-linear programming (MINLP). The optimization model is developed. The objective function defines the material costs of the structure. The objective function is subjected to structural analysis and dimensioning constraints, which are defined according to Eurocode standards. The Modified Outer-Approximation/Equality-Relaxation algorithm $(\mathrm{OA} / \mathrm{ER})$ and the linked multi-level strategy are applied.

A numerical example at the end of the paper shows the efficiency of the proposed optimization approach. In a single optimization procedure, the minimal material costs of the structure, the optimal number of glulam portal frames and steel members as well as all standard/discrete cross-sections are determined.

\section{ACKNOWLEDGEMENTS}

The authors are grateful for the support of funds from the Slovenian Research Agency (program P2-0129).

\section{REFERENCES}

[1] Topping, B.H.V. \& Robinson, D.J., Optimization of timber framed structures. Computers \& Structures, 18(6), pp. 1167-1177, 1984. https://doi.org/10.1016/0045-7949(84) 90161-5

[2] Kaziolasa, D.N., Bekasb, G.Ä., Zygomalasc, I. \& Stavroulakisd, G.E., Life Cycle Analysis and Optimization of a Timber Building. 7th International Conference on Sustainability in Energy and Buildings, Energy Procedia, 83, pp. 41-49, 2015. https://doi. org/10.1016/j.egypro.2015.12.194

[3] Stanić, A., Hudobivnik, B. \& Brank, B., Economic-design optimization of cross laminated timber plates with ribs. Composite Structures, 154, pp. 527-537, 2016. https:// doi.org/10.1016/j.compstruct.2016.07.072

[4] Pech, S., Kandler, G., Lukacevic, M. \& Füssl, J., Metamodel assisted optimization of glued laminated timber beams by using metaheuristic algorithms. Engineering Applications of Artificial Intelligence, 79, pp. 129-141, 2019. https://doi.org/10.1016/j.engappai.2018.12.010

[5] Jelušič, P. \& Kravanja, S., Optimal design of timber-concrete composite floors based on the multi-parametric MINLP optimization. Composite structures, 179, pp. 285-293, 2017. https://doi.org/10.1016/j.compstruct.2017.07.062

[6] Jelušič, P., Determining optimal designs of timber beams with non-uniform crosssection. High Performance and Optimum Design of Structures and Materials III, WIT Transactions on the Built Environment, 175, pp. 169-175, 2019.

[7] Kravanja, S. \& Žula, T., Optimization of a timber hall structure. High Performance and Optimum Design of Structures and Materials IV, WIT Transactions on the Built Environment, 196, pp. 183-192, 2020.

[8] Eurocode 2. Design of concrete structures, European Committee for Standardization, Brussels 2004.

[9] Eurocode 3. Design of steel structures, European Committee for Standardization, Brussels 2005.

[10] Eurocode 5. Design of timber structures, European Committee for Standardization, Brussels 2008. 
[11] Kravanja, Z. \& Grossmann, I.E., New Developments and Capabilities in PROSYN - An Automated Topology and Parameter Process Synthesizer. Computers chem. Eng., 18, pp. 1097-1114, 1994. https://doi.org/10.1016/s0098-1354(94)85027-5

[12] Kravanja, S., Kravanja, Z. \& Bedenik, B.S., The MINLP optimization approach to structural synthesis, Part I: A general view on simultaneous topology and parameter optimization. Int. J. Numer. Methods Eng., 43, pp. 263-292, 1998. https://doi.org/10.1002/ (sici)1097-0207(19980930)43:2<263::aid-nme412>3.0.co;2-u

[13] Kravanja, S., Soršak, A. \& Kravanja, Z., Efficient multilevel MINLP strategies for solving large combinatorial problems in engineering. Optim. Engng., 4, pp. 97-151, 2003. https://doi.org/10.1023/a:1021812414215

[14] Brooke, A., Kendrick, D. and Meeraus, A., GAMS - A User's Guide, Scientific Press, Redwood City, CA, 1988.

[15] WolframAlpha computational intelligence, https://www.wolframalpha.com/.

[16] Vratuša, S. \& Premrov, M., Projektiranje lesenih konstrukcij. Projektiranje gradbenih konstrukcij po Evrokod standardih, Inženirska zbornica Slovenije, pp. 5/1-5/117, 2009.

[17] Kravanja, Z., Challenges in sustainable integrated process synthesis and the capabilities of an MINLP process synthesizer MipSyn. Comput. Chem. Eng., 34(11), pp. 18311848, 2010. https://doi.org/10.1016/j.compchemeng.2010.04.017

[18] Drudd, A.S., CONOPT - A Large-Scale GRG Code, ORSA J. Comput., 6, 207-216, 1994.

[19] Abadie, J. \& Carpentier, J., Generalization of the Wolfe reduced gradient method to the case of nonlinear constraints, Optimization, Academic Press, New York, 1969.

[20] CPLEX User Notes, ILOG inc.

[21] Land, A.H. \& Doig, A.G., An Automatic Method for Solving Discrete Programming Problems, Econometrica, 28(3), pp. 497-520, 1960. https://doi.org/10.2307/1910129 